\title{
Specimen Isolation
}

National Cancer Institute

\section{Source}

National Cancer Institute. Specimen Isolation. NCI Thesaurus. Code C128947.

The act of separating a sub-component from the original collected specimen. 